\title{
The Long-Term Effect of Multichannel Usage on Sales
}

\author{
Tolga Bilgicer • Kamel Jedidi • Donald R. Lehmann • \\ Scott A. Neslin
}

Published online: 6 January 2015

(C) Springer Science+Business Media New York 2014

\begin{abstract}
The paper investigates the long-run consequences of multichannel shopping on customers' spending. Using data from a major US catalog company which introduced an online channel, our results validate previous findings that multichannel customers spend more than mono-channel customers in the short run. However, the difference in spending dissipates over time with multichannel customers reverting to their regular consumption pattern in 3 years. As our results are based on observational data, we use different panel data econometric models and combine them with propensity score matching methods to control for potential self-selection biases. Our key results are consistent across the analysis methods.
\end{abstract}

Keywords Multichannel usage $\cdot$ Sales $\cdot$ Spending ·

Self-selection $\cdot$ Matching

The views expressed in this article are solely those of the authors, who are responsible for the content, and do not necessarily represent the views of Cornerstone Research.

T. Bilgicer $(\bowtie)$

Cornerstone Research, Washington, DC 20006, USA

e-mail: hbilgicer13@gsb.columbia.edu

K. Jedidi • D. R. Lehmann

The Graduate School of Business, Columbia University, New York, NY 10027, USA

K. Jedidi

e-mail:kj7@columbia.edu

D. R. Lehmann

e-mail:dr12@columbia.edu

S. A. Neslin

Tuck School of Business at Dartmouth, Hanover, NH 03755, USA

e-mail: scott.a.neslin@dartmouth.edu

\section{Introduction}

Recent technological advances and fierce competition have led many companies to expand the channel through which customers can purchase their products. In many product categories, customers have a broad range of channels to choose from, such as catalogs, call centers, Internet stores, apps for smartphones, and bricks-and-mortar stores.

Previous research has investigated what happens when customers start using more than a single channel (i.e., become multichannel). This research stream has identified two key consequences of multichannel usage. First, Shankar et al. [1] and Hitt and Frei [2] find that customers using Internet channel in addition to the traditional bricks-and-mortar channel are more loyal than customers who use a single channel. Sousa and Voss [3] explain the higher customer retention rates by increased coordination between channels: the coordination among channels increases customer satisfaction, which improves retention rates. Second, Thomas and Sullivan [4], Kumar and Rajkumar [5], Venkatesan et al. [6], Ansari et al. [7], and Kushwaha et al. [8] find that, on average, multichannel customers spend more than single-channel customers. This research stream, however, has measured customers' spending using cross-section data and has not attempted to quantify the long-term effects of multichannel usage on household spending.

Blattberg et al. [9] point out that multichannel customers could buy more due to self-selection: a heavy user is more likely to be able to take advantage of the availability of several channels. In this argument, multichannel usage does not cause (or lead to) higher revenues; the heavy users self-select into using multiple channels. Thus, the direction of causality between increased overall spending and utilizing more than one channel is not clear.

This study empirically examines the long-term consequences of multichannel usage on consumers' spending, while 
controlling for potential self-selection through a variety of statistical methods. To address the self-selection problem, we use five different panel data econometrics techniques (i.e., pooled OLS, fixed effects, first difference, lagged dependent variable, and Arellano-Bond generalized method of moments GMM, estimation). We also implement propensity score matching to create datasets consisting of matched pairs. Matching is a commonly used technique to cope with selfselection problems in social sciences [10-13]. By artificially creating observationally equivalent control and treatment groups, propensity score matching enables us to compare single-channel and multichannel customers with similar observed characteristics.

In line with prior research, we find that multichannel customers spend more on average even when we control for the self-selection bias. However, we contribute to the literature by showing that this increased spending decays over time. Specifically, the difference between multi- and mono-channel customers' spending disappears 3 years after mono-channel customers become multichannel customers. This result can be explained by novelty theory. According to this theory, customers derive value from learning new ways of doing things [14], but they return to their regular consumption patterns in the long run [15-18]. Alternatively, this decay could be related to the type of the new sales channel that consumers begin to use. Blattberg et al. [9] posit that online channel usage in the long run leads customers to compare competitors' products and prices and become more price-sensitive over time. Ansari et al. [7] provide empirical support for this argument.

The rest of the paper is organized as follows. We first describe relevant research and highlight our contributions. Next, we discuss the data and present the methodologies we use to analyze the data. We then present empirical results. We conclude with a discussion on managerial implications and directions for future research.

\section{Related Literature and Contributions of the Paper}

The main objective of our research is to examine how the spending patterns of multichannel customers evolve over time as compared to mono-channel customers. In this section, we review the pertinent literature and highlight our research contributions.

\subsection{Impact of Multichannel Usage on Revenues}

Most findings in the marketing literature suggest that multichannel customers purchase more than mono-channel customers (e.g., $[4,5,7,8,19])$. However, Thomas and Sullivan [4] point out that using any combination of two channels does not necessarily result in higher purchase volume than a single channel. For instance, consumers using catalog and online channels could buy (on average) less than customers using only a bricks-and-mortar store. However, these customers typically purchase more than only online or catalog channel customers.

Few scholars have examined the long-term consequences of multichannel usage on customers' spending habits. Avery et al. [20] investigate the cannibalization and complementary effects of adding bricks-and-mortar stores to existing Internet and catalog channels. The authors find that opening retail stores reduces sales in the catalog channel in both short and long run. However, while new bricks-and-mortar stores cannibalize the sales in the online channel in the short term, they produce a complementary effect (i.e., increasing sales) in the long run. Pauwels and Neslin [21] find that catalog mailings enhance sales not only of the catalog channel but also of the online and retail store channels in both short and long run. All these researchers, however, report aggregate channel sales effects and do not distinguish between increases in sales stemming from newly acquired customers and those stemming from existing customers. In this paper, we use household-panel data to investigate the sales effect of multichannel behavior on existing customers over time.

\subsection{Self-Selection}

A heavy user is more likely to select a multichannel firm over a single-channel company. It is highly possible that customers using more than one sales channel are inherently different than customers who use a single channel. For example, Hitt and Frei [2] find that consumers who adopt online banking channel have always been more profitable. In contrast, Ansari et al. [7] find no differences in the spending of multichannel and mono-channel customers. This implies that self-selection problem may not be present in their case. As these results are contradictory, the literature can benefit from further work quantifying the relationship between customer spending and multichannel usage, while addressing the self-selection problem. In addition, while these papers have examined only the short-term effects of multichannel usage, we examine both short- and long-run impact of multichannel usage in this study.

\subsection{Methodology}

To address the self-selection problem, researchers typically use different panel data econometric techniques, instrumental variable estimation, or matching methods [22]. In this study, we estimate five different panel data econometrics models on "matched" data based on observed customer characteristics. To the best of our knowledge, this study is the first to combine a dynamic panel data model with the propensity score matching method.

Several papers in the social sciences rely on aggregatelevel data (such as US Census data or demographics at zip 
code) to create matched pairs. These papers are criticized as some scholars (e.g., [23]) argue that zip code-level data do not provide sufficient information to construct functional matched pairs. Our household-level data enable us to create matched pairs based on both US Census and household-level data. We compare the estimation results using data generated by both matching approaches.

To summarize, we contribute to the marketing literature by examining both short- and long-term effects of multichannel usage on consumers' spending. We minimize self-selection by using panel data econometric techniques and the propensity score matching method. That is, we run different panel data econometrics models on data consisting of matched pairs. Methodologically, our paper is the first study to use Arellano-Bond estimation in conjunction with propensity score matching. Further, we compare and contrast the estimation results obtained using matched pairs based on aggregateand household level data.

\section{Data}

The data provider is a major retailer in the USA that sells durables and apparel in mature categories predominantly through catalog channel. The panel data are reported yearly at the household level, starting on January 1, 1997, and ending on December 31, 2001. The retailer introduced an online channel in 1996. However, the vast majority of customers (i.e., more than $99.9 \%$ ) did not try the Internet channel before 1997, when we begin to observe them. ${ }^{1}$

The data include channel-specific sales amounts, marketing activities (catalogs and e-mails), and household-specific demographics. The catalog company also provides us with recency, frequency, and monetary value (RFM) measures for each household prior to the beginning of the data. We also create a set of dummy variables that capture each household's unique multichannel shopping behavior. Specifically, year-ofmultichannel $_{i j t}=1$ if as of year $t$, customer $i$ became multichannel $j$ (where $j=1, \ldots, 5$ ) years ago; and year-ofmultichannel $_{i j t}=0$ otherwise. For instance, in the first year that household $i$ starts using the online channel, first-year-ofmultichannel $_{i 1 t}$ is 1 , while other dummy variables, such as second-year-of-multichannel ${ }_{i 2 t}$ and third-year-ofmultichannel $_{i 3 t}$ are 0 . In the next year, first-year-of-

\footnotetext{
${ }^{1}$ We exclude the households that tried the Internet channel prior 1997 from the analysis.

${ }^{2}$ Note that we do not assess whether households use more than one channel in the following years of becoming a multichannel user. We treat the act of becoming multichannel user as the "treatment" and measure this act's influence on consumers' spending in the long run. Although customer migration between channels is a very interesting topic, it has been investigated before. See for example, Ansari et al. [7].
}

multichannel $_{i 1 t}$ is 0 and second-year-of-multichannel ${ }_{i 2 t}$ is 1 , indicating that the household is a second year multichannel user, and so forth. ${ }^{2}$ Table 1 lists the variables we use and their operationalization.

The company has survey-based demographics data about their customers (Table 2 depicts households' descriptive statistics across all the years we observe them). To add information regarding customers' formal education level, we integrate data from the National Center for Environmental Health $(\mathrm{NCEH})$ website into the primary dataset. ${ }^{3}$ NCEH's data provide the distribution of formal education levels for adults older than 25 years at zip code level. By calculating the percent of college-educated people within each zip code, we create a proxy for the probability that the household head has a college degree.

The main analysis focuses on customers who add the online channel to the incumbent catalog channel that they already use. Table 2 presents the sample means and standard deviations for the overall sample and multichannel and singlechannel households. According to this table, multichannel users spend significantly more than mono-channel users. Moreover, multichannel customers are younger, are better educated, and have higher incomes and more children compared to single-channel users. In addition, multichannel households are more frequent buyers and are exposed to more marketing activities. This latter result suggests a potential endogeneity issue, which we address in our empirical analysis.

\section{Empirical Analysis}

In an ideal scenario, we would conduct an experiment to measure the long-term effects of multichannel usage on consumers' total spending. This way, we would randomly assign a set of households to the treatment group (multichannel) and another set to the control group (mono-channel) and track their purchase behavior over time. Analyzing such experimental data would provide clean results that are free of bias stemming from the self-selection problem. Unfortunately, it is difficult to run such an experiment since it is impossible to force customers to use multiple channels. This explains why most empirical researchers rely on observational data to study multichannel issues. However, using observational data suffers from self-selection bias: the households who use multiple channels may be different from those who use a single channel from the beginning. For example, the multichannel households could differ in their usage level before becoming multichannel so that difference in purchase behavior cannot solely be attributed to being multichannel. This is quite possible in

\footnotetext{
${ }^{3}$ This zip code level dataset can be obtained from the NCEH's website free of charge at http://www.cdc.gov/nceh.
} 
Table 1 Operationalization of variables

\begin{tabular}{|c|c|}
\hline Variable & Description \\
\hline Total spending & $\begin{array}{l}\text { Household's total spending in thousand US } \\
\text { dollars in the current year }\end{array}$ \\
\hline $\begin{array}{l}\text { First year of } \\
\quad \text { multichannel }_{i 1 t}\end{array}$ & $\begin{array}{l}\text { Dummy variable indicating household } i \text { became } \\
\text { multichannel user } 1 \text { year ago at time } t\end{array}$ \\
\hline $\begin{array}{l}\text { Second year of } \\
\quad \text { multichannel }_{i 2 t}\end{array}$ & $\begin{array}{l}\text { Dummy variable indicating household } i \text { became } \\
\text { multichannel user } 2 \text { years ago at time } t\end{array}$ \\
\hline $\begin{array}{l}\text { Third year of } \\
\text { multichannel } \\
i 3 t\end{array}$ & $\begin{array}{l}\text { Dummy variable indicating household } i \text { became } \\
\text { multichannel user } 3 \text { years ago at time } t\end{array}$ \\
\hline $\begin{array}{l}\text { Fourth year of } \\
\text { multichannel }_{i 4 t}\end{array}$ & $\begin{array}{l}\text { Dummy variable indicating household } i \text { became } \\
\text { multichannel user } 4 \text { years ago at time } t\end{array}$ \\
\hline $\begin{array}{l}\text { Fifth year of } \\
\quad \text { multichannel }_{i 5 t}\end{array}$ & $\begin{array}{l}\text { Dummy variable indicating household } i \text { became } \\
\text { multichannel user } 5 \text { years ago at time } t\end{array}$ \\
\hline Customer tenure & $\begin{array}{l}\text { Years passed since household's first purchase; we } \\
\text { use the natural logarithm of the customer } \\
\text { tenure to capture the nonlinear effect of } \\
\text { customers' familiarity }\end{array}$ \\
\hline $\begin{array}{l}\text { Probability of college } \\
\text { education }\end{array}$ & Percent of college-educated people in the zip code \\
\hline $\begin{array}{l}\text { Number of kids in } \\
\text { household }\end{array}$ & Number of children within the household \\
\hline $\begin{array}{l}\text { Head of household's } \\
\text { age }\end{array}$ & Head of the household's age in years \\
\hline Household income & Household's annual income in US dollars \\
\hline $\begin{array}{l}\text { Past purchase } \\
\text { incidences }\end{array}$ & $\begin{array}{l}\text { Household's cumulative number of previous } \\
\text { purchases }\end{array}$ \\
\hline $\begin{array}{l}\text { Number of catalogs } \\
\text { received }\end{array}$ & Number of catalogs received in the current year \\
\hline E-mail subscription ${ }_{t}$ & $\begin{array}{l}\text { Whether the household opted in or opted out to } \\
\text { receive commercial e-mails from the company } \\
\text { at time } t\end{array}$ \\
\hline $\begin{array}{l}\text { Number of e-mails } \\
\text { received }\end{array}$ & Number of e-mails received in the current year \\
\hline Year 3 & Dummy variable for the third year of sample data \\
\hline Year 4 & $\begin{array}{l}\text { Dummy variable for the fourth year of sample } \\
\text { data }\end{array}$ \\
\hline Year 5 & Dummy variable for the fifth year of sample data \\
\hline
\end{tabular}

our data since customers with higher predispositions to become multichannel are more likely to be heavy users [9]. Econometrically, the self-selection bias induces a correlation between the customer decision to become multichannel and the model error term. Failure to control for this endogeneity problem will lead to biased empirical results.

There are several econometric approaches for addressing the self-selection problem, such as panel data econometrics, instrumental variable estimation, and matching methods [22]. In this section, we briefly review the panel data econometric models that we use to address the self-selection problem. We then discuss the propensity score matching method and explain how we implemented it in our study. As we do not have good instruments, we do not use instrumental variable estimation in our analysis.

\subsection{Panel Data Econometrics Models}

\subsubsection{Pooled Ordinary Least Squares}

We use pooled ordinary least squares (POLS) regression as a benchmark model. The strategy here is to include the variables that correlate with sales and the decision to become multichannel directly in the sales equation. As a result, these variables are not part of the error term. To reduce the selfselection bias in POLS, [24], chapter 3) suggest including customer demographics as independent variables. To control for period effects, we include year-specific dummy variables in the model, as we are not interested in the nonparametric relationship between multichannel usage and household spending. Let $y_{i t}$ be household $i$ 's total spending in year $t$ in US dollars. Let year-of-multichannel ${ }_{i j t}(j=1, \ldots, 5)$ be a dummy variable that indicates whether household $i$ is multichannel for $j$ years in year $t$. Specifically, these dummy variables indicate whether the household is a first-, second-, third-, fourth-, or fifth-year multichannel user at time $t$. For instance, "first-year-of-multichannel ${ }_{i 1 t}$ " is 1 when household $i$ became

Table 2 Descriptive statistics

\begin{tabular}{llll}
\hline Variable & $\begin{array}{l}\text { All households } \\
\text { Mean (standard deviation) }\end{array}$ & $\begin{array}{l}\text { Multichannel households } \\
\text { Mean (standard deviation) }\end{array}$ & $\begin{array}{l}\text { Single-channel households } \\
\text { Mean (standard deviation) }\end{array}$ \\
\hline Total spending (in US dollars) & $146.95(302.66)$ & $210.72(362.88)$ & $128.17(279.87)$ \\
Purchase frequency & $1.20(0.97)$ & $1.37(1.10)$ & $1.15(0.92)$ \\
Customer tenure (in years) & $12.06(3.84)$ & $11.93(3.53)$ & $12.15(3.94)$ \\
Head of household's age (in years) & $50.11(13.16)$ & $45.67(11.17)$ & $51.38(13.42)$ \\
Household income (in thousand US dollars) & $99.53(42.18)$ & $108.51(39.20)$ & $96.90(42.65)$ \\
Number of kids in household & $0.46(0.92)$ & $0.62(1.04)$ & $0.42(0.88)$ \\
Probability of college education & $0.38(0.16)$ & $0.41(0.16)$ & $0.38(0.16)$ \\
Number of catalogs received & $22.53(20.76)$ & $27.66(24.55)$ & $21.04(19.28)$ \\
Number of e-mails received & $2.05(9.10)$ & $6.61(16.29)$ & $0.73(4.70)$ \\
Sample size & 55,070 & 12,350 & 42,720 \\
\hline
\end{tabular}


multichannel user 1 year ago as of year $t$. In the following year, this variable becomes 0 and "second-year-ofmultichannel $_{i 2 t}$ " variable becomes 1 .

Previous research has not studied the sales impact of multichannel usage over time (i.e., it has typically examined the effect of first-year-of-multichannel on sales). All the households in our sample use the catalog channel for purchasing. Thus, we consider the adoption of the new online channel as equivalent to becoming a multichannel household.

The POLS model is specified as follows:

$$
\begin{aligned}
y_{i t}= & \gamma+\sum_{j=1}^{5} \rho_{j} \text { year-of-multichannel }{ }_{i j t} \\
& +\sum_{m=1}^{M} \beta_{m} x_{m i t}+\lambda_{t}+\varepsilon_{i t}
\end{aligned}
$$

where $\gamma$ is an intercept term and $\rho_{j}(j=1, \ldots, 5)$ are the parameters of interest that measure the long-term effects of multichannel usage on consumers' total spending. The vector $\boldsymbol{x}_{i t}=\left(x_{1 i t}, \ldots x_{M i t}\right)^{\prime}$ includes the $M$ independent control variables that are listed in Table 1 and discussed in detail below. $\boldsymbol{\beta}=\left(\beta_{1}, \ldots, \beta_{M}\right)^{\prime}$ is a vector of parameters, and $\lambda_{t}$ denotes a set of period effects that capture common trends in all consumers' total spending and $\varepsilon_{i t}$ is an error term for capturing all other omitted factors. We assume that $\varepsilon_{i t}$ is normally distributed with mean zero and variance $\sigma^{2}$ for all $i$ and $t$.

We include the following control variables in our analysis: the firm's marketing efforts, consumer demographics, and socioeconomic factors. Marketing activities have considerable impact on consumers' spending $[6,7]$ and channel choice $[6$, 7]. Demographic and socioeconomic factors impact consumers' spending as well propensity to become multichannel. Venkatesan et al. [6] and Ansari et al. [7] find that younger customers with high income tend to spend more. Such customers are also more likely to try new channels (37). As formal education is highly correlated with income, and influences consumers' channel choice Mattilla et al. [25], we include our proxy for education level in our analysis. The number of children within a household directly influences the household's disposable income, consumers' spending [7], and a household's inclination to become multichannel. Customer tenure has been shown to be associated with multichannel shopping Kumar and Rajkumar [5]; [4]), and therefore is included in our model.

Marketing variables are likely to be endogenous since companies target their marketing efforts to their best customers [9]. Conventionally, companies typically use basic statistical models, such as RFM models, to identify the best customers [9]. Following Ansari et al. [7] and Blattberg et al. ([9], p. 652), we control for such a potential endogeneity problem by including a RFM variable (i.e., cumulative purchase incidences) in our analysis. However, a single RFM variable may not control for additional factors influencing firm's managers use to allocate marketing effort for a given customer. To control for such additional factors, Risselada et al. [26] recommend including average marketing variable per period per each household. This is because the mean marketing effort across all periods serves as a proxy for additional factors besides RFM-type variables affecting marketing efforts.

Even with the rich set of control variables we use, the POLS model does not fully control for the self-selection problem. Particularly, inclusion of demographic variables as covariates controls only for observed heterogeneity. Nonetheless, Angrist et al. [24] point out that the POLS model impressively minimizes self-selection and causality biases when customer demographics are included as explanatory variables. To control for unobserved household heterogeneity, we utilize a fixed-effects (FE) specification as our next model.

\subsubsection{Fixed Effects}

The FE model extends POLS by specifying a customer-specific effect to account for unobserved, time-invariant customer heterogeneity. This model can effectively address the selfselection problem if unobserved heterogeneity or omitted time-invariant household characteristics underlie the self-selection process. For instance, the households may have different levels of "ability," which influences their spending levels and their propensity to become multichannel users. Obviously, if customer ability evolves over time, then the FE model will still suffer from endogeneity (i.e., correlation between the error component and the model covariates) due to omitted time-varying components.

The FE model is specified as follows:

$$
\begin{aligned}
y_{i t}= & \gamma+\sum_{j=1}^{5} \rho_{j} \text { year-of-multichannel }{ }_{i j t} \\
& +\sum_{m=1}^{M} \beta_{m} x_{m i t}+\lambda_{t}+\mu_{i}+\varepsilon_{i t}
\end{aligned}
$$

where $\mu_{i}$ denotes the unobservable, time-invariant, householdspecific fixed effect. The FE model has one main disadvantage: its specification cancels out all of the time-invariant household-specific characteristics, such as demographics and socioeconomic factors, from the analysis.

Another way of coping with unobserved, time-invariant customer heterogeneity is using first-difference specification, which we discuss in the next section. 


\subsubsection{First Difference}

The first-difference (FD) model "differences out" the customer-specific effect by subtracting the $(t-1)$ th equation from the $t$ th equation. Similar to the FE model, the FD model only controls for time-invariant, unobserved heterogeneity $([27,28])$. The FD model is specified as follows:

$$
\begin{aligned}
y_{i t}-y_{i t-1}= & \sum_{j=1}^{5} \rho_{j}\left(\text { year-of-multichannel }_{i j t} \text {-year-of-multichannel }{ }_{i j t-1}\right) \\
& +\sum_{m=1}^{M} \beta_{m}\left(x_{m i t}-x_{m i t-1}\right)+\lambda_{t}+\left(\varepsilon_{i t}-\varepsilon_{i t-1}\right)
\end{aligned}
$$

The FD model has two disadvantages. First, similar to the FE model, it wipes out all of time-invariant household-specific characteristics. Second, the standard errors estimated by ordinary least squares method will be biased, as the error terms in the FD model are correlated across observations. Therefore, we use Huber-White sandwich estimators to remedy this problem.

\subsubsection{Lagged Dependent Variable}

Neither the FE nor the FD models account for time-varying, unobserved heterogeneity. To control for this potential source of bias, we use a lagged dependent variable (LDV) model as our fourth model. Unobserved heterogeneity (or ability) may change over time as a result of learning or maturation. The LDV model captures this changing unobserved heterogeneity by using the lagged dependent variable as a proxy. The LDV model specification is:

$$
\begin{aligned}
y_{i t}= & \gamma+\alpha y_{i t-1}+\sum_{j=1}^{5} \rho_{j} \text { year-of-multichannel }{ }_{i j t} \\
& +\sum_{m=1}^{M} \beta_{m} x_{m i t}+\lambda_{t}+\varepsilon_{i t}
\end{aligned}
$$

where the lagged value $y_{i t-1}$ is included in the model to capture persistence in a household's spending and also to control for the self-selection in multichannel usage since multichannel users tend to be heavy users $[2,9]$. The advantage of a LDV model is that it controls for both time-invariant and time-variant unobserved heterogeneity. However, such a control comes with a heavy price: the lagged dependent variable and the model error term are correlated, and consequently, the results will be biased. To address this, we use the ArellanoBond generalized method of moments (A-B GMM) estimation as our final model.

\subsubsection{Arellano-Bond GMM}

This method (also referred as dynamic panel data estimation) combines the essence of the LDV and the FE models. This model accounts for the unobserved time-invariant household characteristics, does not require these latent characteristics to be uncorrelated with other covariates, and allows for dynamic structure (i.e., including the lagged dependent variable in the regression). This model is specified as:

$$
\begin{aligned}
y_{i t}= & \gamma+\alpha y_{i t-1}+\sum_{j=1}^{5} \rho_{j} \text { year-of-multichannel }{ }_{i j t} \\
& +\sum_{m=1}^{M} \beta_{m} x_{m i t}+\lambda_{t}+\mu_{i}+\varepsilon_{i t}
\end{aligned}
$$

Note that $y_{i t-1}$ is persistently correlated with the error structure in Eq. (5). In addition, because $\mu_{i}$ appears in each time period, the model cannot be estimated through simple least square estimation procedures. Anderson and Hsiao [29] suggest first differencing the equation to remove fixed household effects and using lagged explanatory variables as instruments to create moments for estimation. Arellano and Bond [30] suggest using deeper lags (i.e., two or more periods) as instruments for GMM estimation to achieve more efficiency.

\subsection{Matching Methods}

The goal of matching methods is to mimic experimental designs by pairing treated and untreated customers who have comparable characteristics but not treatments [22]. That is, the objective of the matching methodology is to artificially create treatment and control groups. These methods rely on the assumption that the observed characteristics are informative enough that controlling for them is sufficient to remove any self-selection effect, referred to as the "conditional independence assumption." A rich dataset on observed heterogeneity is required to meet the conditional independence assumption [24].

The most commonly used matching methods are (i) covariate matching (Avery et al. [46]; [2, 31]) and (ii) propensity score matching ([32]; Mithas et al. [33]; [13, 23, 28, 34]). The covariate matching pairs multichannel and mono-channel households based on observed household demographics and socioeconomic factors. This method, however, comes with inherent problems: utilizing many customer characteristics to find similar treated and untreated customers is tremendously challenging $[1,2,31]$. One way to cope with this problem is to reduce the dimensions of data by using the propensity score matching (PSM). 
To create matched pairs, PSM uses the conditional probability that a customer with particular observed characteristics becomes a multichannel user. A logistic model estimates the propensity score for each household to become multichannel shopper. Because PSM reduces each consumer's propensity to a single score, a matched pair with highly similar propensity scores may, in fact, have different household characteristics $[22,24]$. However, Smith et al. [34] find that PSM performs vastly better than the covariate matching method. Therefore, we use PSM to pair multichannel and single-channel households.

Let $\mathrm{MC}_{i}$ indicate if household $i$ is a multichannel user by the last period of the data $\left(\mathrm{MC}_{i}=1\right)$, or not $\left(\mathrm{MC}_{i}=0\right)$. Following previous research, we use the following logistic regression model to estimate the propensity scores:

$P\left(\mathrm{MC}_{i}=1\right)=1 /\left(1+\exp \left(\eta+\sum_{j=1}^{J} \delta_{j} z_{i j}\right)\right)$

where $z_{i}=\left(z_{i 1}, \ldots z_{i J}\right)^{\prime}$ are $J$ observed household characteristics (discussed below), $\eta$ is an intercept, and $\delta=\left(\delta_{1}, \ldots, \delta_{J}\right)^{\prime}$ is a vector of regression parameters.

We perform two kinds of propensity score estimations: the first is based on household characteristics measured at the zip code level (i.e., US Census data on education, median age, median income, and average family size). The second uses household-level characteristics (i.e., head of household's age, household income, and number of children in the household). As Heckman et al. [10] point out, only variables that are unaffected by the treatment should be included in the matching logistic model. Therefore, we do not include dynamic variables, such as spending, incidence decisions, or updated RFM-type variables, in this regression. In our data, the household-level characteristics were measured before the household became multichannel. Similarly, census-level characteristics are not likely to be affected by the observed households' decision to become multichannel, as we observe only a small subset of households living in each zip code.

We use the logistic parameter estimates to predict the propensity score for each household and implement the nearest neighbor algorithm to create matched pairs. ${ }^{4}$ There are several variants of the nearest neighbor algorithm, such as with or without replacement. We select the algorithm without replacement, where a household can be matched only once, and therefore, eliminate the risk of artificially giving more

\footnotetext{
${ }^{4}$ These estimation results are available upon request from the corresponding author. For our logistic regressions, we standardized household characteristics. Then, we estimated each household's propensity score (that are between 0 and 1) based on the results of the logistic estimation. Finally, we used Stata's NNMatch procedure to create matched household pairs based on the estimated propensity scores.
}

weight to some households in our analysis. Any unmatched household is dropped from the dataset and not included in the regressions. To ensure there are no ordering effects during the matching process, we randomize the order of data before matching.

\subsection{Combining Panel Data Econometrics with Propensity Score Matching}

Our rich data enable us to compare the results of matching based on aggregate- and household-level variables and address an ongoing debate in literature: several papers in the social sciences rely on aggregate-level data to create matched pairs. For example, Avery et al. [20] and Degeratu et al. [31] use US census data at zip code level to generate matched pairs. Gensler et al. [13, 23] and Heckman and Navarro-Lozano [22] criticize the use of aggregate-level data for matching purposes. They argue that aggregate-level data do not provide enough information to construct functional matched pairs. Fortunately, our data contain household-level demographics. By adding US Census variables to the main data, we create two scenarios of matching: matched pairs based on (i) US Census data (measured at the zip code level) and matched pairs based on (ii) household-level data. We compare the results obtained by analyzing the datasets created under these two scenarios.

In sum, we estimate the five different econometric specifications (POLS, FE, FD, LDV, and A-B GMM) on three different datasets: (i) no matching, (ii) matched pairs based on zip code-level demographics, and (iii) matched pairs based on household-level characteristics. Using panel data econometric techniques in conjunction with matching methods is relatively new, and to the best of our knowledge, our study is the first one combining a dynamic panel data econometrics model with the propensity score matching.

\section{Empirical Results}

Most of the econometrics specifications fit the data well. Adjusted $R^{2}$ statistics of POLS, LDV, and FE models are between 37 and $57 \%$ across the three datasets. ${ }^{5}$ Tables 3, 4, and 5 report the estimation results on the full data, matched pairs based on US Census variables, and matched pairs relying on household factors, respectively.

\footnotetext{
${ }_{5}^{5}$ As FD model examines the changes in differences between the dependent and independent variable, this method provides much lower adjusted $R^{2}$ statistics. In addition, as the Arellano-Bond estimation uses GMM to estimate parameters, $R^{2}$ statistic is not calculated for this method (see for example, [35]).
} 


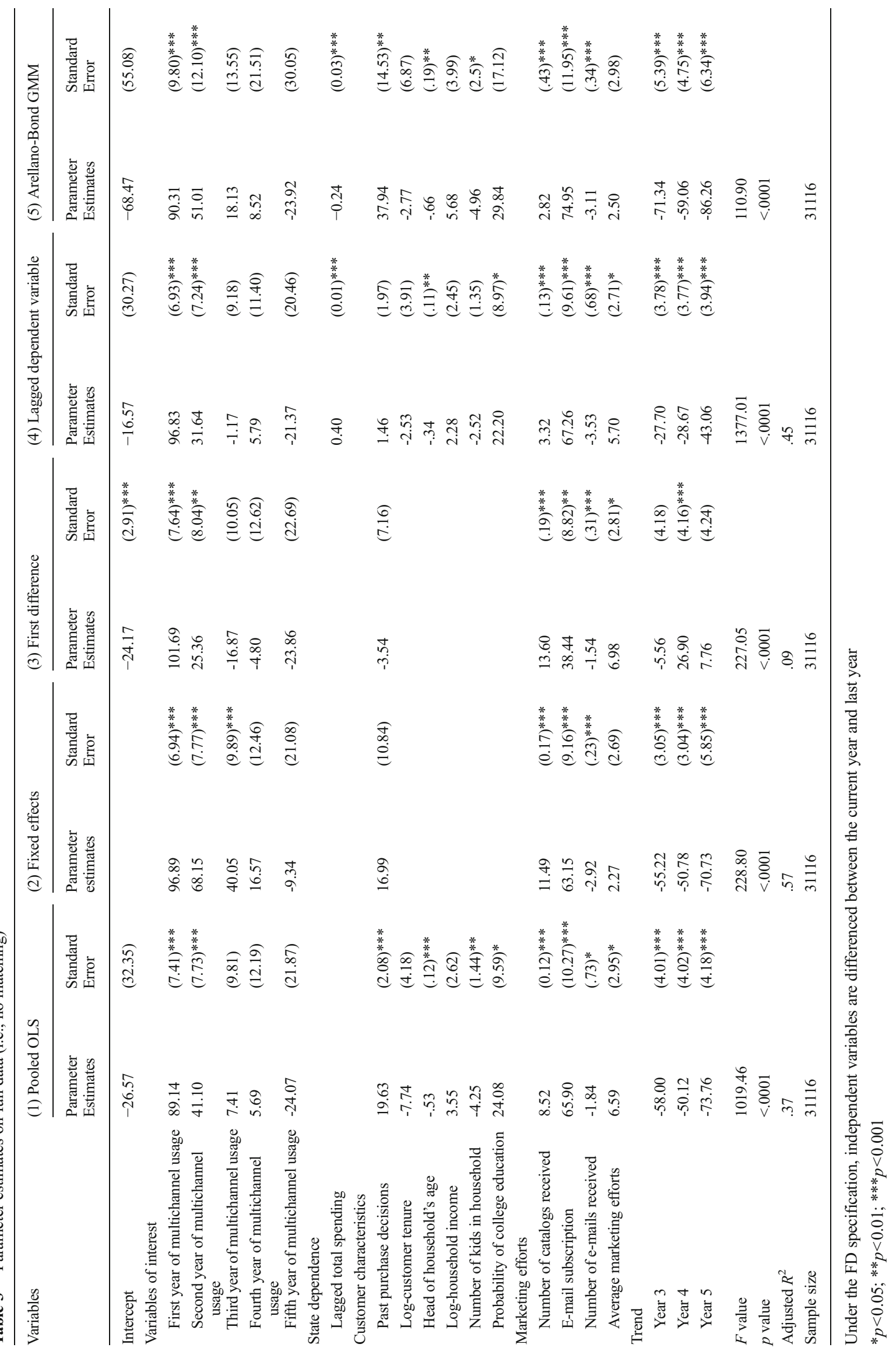




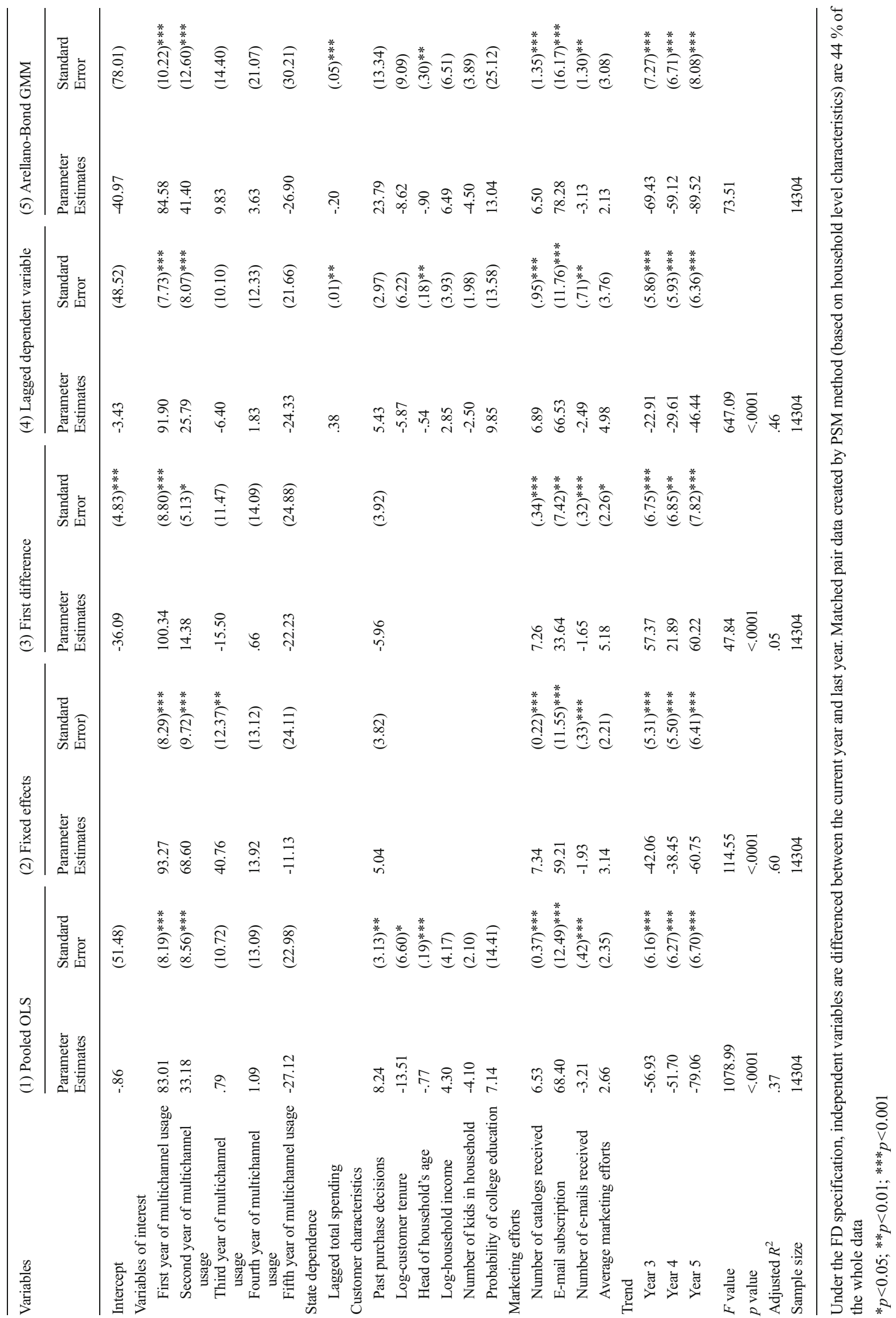




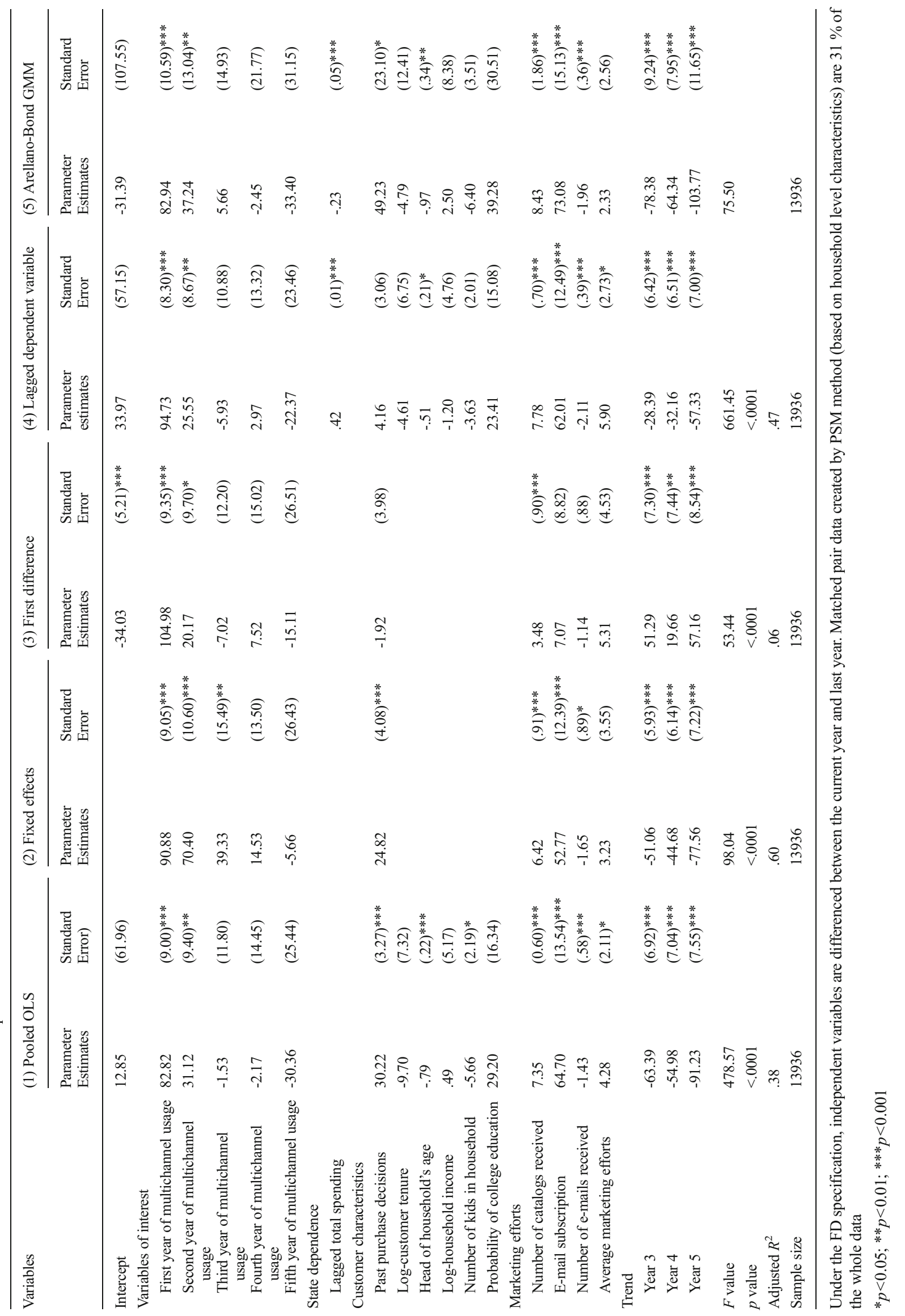




\subsection{Results Based on Full Data}

Table 3 depicts the results when the econometrics models are estimated on the full data. The results are reasonably consistent.

\subsubsection{The Effect of Multichannel Usage}

Across all models, multichannel customers spend much more than mono-channel customers in the first year they become multichannel. Across all models, the coefficients pertaining to the first year of multichannel usage are significant $(p<0.001)$ and vary from $\rho_{1}=89.14$ (POLS) to $\rho_{1}=101.69$ (FD). In their second year of being multichannel, customers still spend significantly more than monochannel customers albeit with a lower magnitude. Across all models, the coefficients pertaining to the second year of multichannel usage are significant $(p<0.001)$ and vary from $\rho_{2}=25.36$ (FD) to $\rho_{2}=68.15$ (FE). On average, multichannel customers spend $\$ 94.97$ (\$43.45) more than mono-channel customers in their first (second) year of becoming multichannel. These results are consistent with results in the marketing literature that multichannel customers spend more on average than mono-channel customers ([4, 5, 7, 19]; Kushwaha and Shankar [36]).

In the long run (after year two), however, the difference between multichannel and mono-channel customers' spending disappears. Starting from the third year of being multichannel, the spending levels of multichannel and mono-channel customers are not significantly different $(p>0.05) .^{6}$ This result provides evidence that multichannel customers revert to their regular spending patterns within a few years of becoming multichannel. In Section 6, we provide potential explanations for why multichannel customers regress to their previous spending pattern over time.

\subsubsection{The Effect of Control Variables}

The estimation results of the control variables are consistent with previous findings. Past purchase incidence (RFM), which we included to control for endogeneity of marketing efforts, is positively associated with spending, suggesting that more frequent buyers spend more. Its effect is significant in the POLS $(p<0.001)$ and A-B GMM $(p<0.01)$ models and ranges from $\beta=19.63$ (POLS) to $\beta=37.94$ (A-B GMM). However, its effect is insignificant $(p>0.05)$ for the FE, FD, and LDV models. This result is not surprising since $y_{i t-1}$ can be a proxy for past purchase incidence. Across the different models, we find that

\footnotetext{
${ }^{6}$ Only under the FE model specification, the third year of being multichannel has a positive and statistically significant impact $\left(\rho_{3}=40.05 ; p<0.001\right)$.
}

younger customers spend more than older customers. This effect is significant $(p<0.01)$ across models and ranges from $\beta=-0.66$ (A-B GMM) to $\beta=-0.34$ (LDV). Similarly, the number of children in the household is negatively associated with customers' spending. Except for the LDV model, this effect is significant $(p<0.05)$ and ranges from $\beta=-4.96$ (A-B GMM) to $\beta=-2.52$ (LDV). Education is positively and significantly ( $p<$ 0.05 ) correlated with spending, with effects ranging from $\beta=$ 22.20 (LDV) to $\beta=24.08$ (POLS). All these results support the previous findings in the literature $[6,7,37]$. Customer tenure and income are not significantly related $(p>0.05)$ to customer spending.

The number of catalogs received has a positive and significant $(p<0.001)$ impact on customers' spending, with effects ranging from $\beta=2.82$ (A-B GMM) to $\beta=13.60$ (FD). Whether a customer subscribes to receive e-mails is also positively and significantly $(p<0.001)$ associated with spending. The effects range from $\beta=38.44$ (FD) to $\beta=74.95$ (A-B GMM). Interestingly, the number of e-mails received is negatively and significantly $(p<0.001)$ correlated with consumers' spending. The effects range from $\beta=-3.53$ (LDV) to $\beta=-1.54$ (FD). This result suggests that the company may be over-e-mailing its customers. Pew Research Center [38], Morimoto and Chang [39], and Ellis-Chadwick and Doherty [40] conclude that consumers perceive a high number of commercial e-mails as exceedingly intrusive and irritating, as they are annoyed by the volume and repetitive nature of such e-mails. Finally, average marketing efforts, a variable that we included to control for endogeneity, is significant for the POLS, FD and LDV models $(p<0.05)$, ranging from $\beta=5.70$ (LDV) to $\beta=6.98$ (FD).

The state dependence variable shows a significant positive effect $(\beta=0.40, p<0.001)$ for the LDV model, but its effect is negative $(\beta=-0.24, p<0.001)$ for the A-B GMM model. This suggests that after correcting for the auto-correlated errors and customer observed heterogeneity, a household's current spending is negatively correlated with their previous spending; households that made large purchases last year are more likely to make small purchases in the current year. Finally, the dummy variables capturing the time trend indicate that the households in our dataset tend to decrease their spending over time.

\subsection{Results Based on Propensity Score Matching Using US Census Data}

This PSM method uses US Census data to create matched pairs, and the resulting data are approximately $44 \%$ of the original, full data. Table 4 depicts the estimates of the same five models using these matched pairs. To the best of our knowledge, this study is the first to estimate a dynamic 
panel data model on matched data based on propensity scores.

\subsubsection{The Effect of Multichannel Usage}

The results in Table 4 are similar to those in Table 3. Except for the FE model, multichannel usage is significantly associated $(p<0.001)$ with increased overall spending in the first 2 years. Thereafter, the difference between multichannel and mono-channel customers is insignificant $(p>0.05)$. These results are consistent with our previous findings based on the full data. The FE model shows that multichannel customers spend significantly more $(p<0.001)$ than mono-channel customers for the first 3 years. Comparing the PSM results in Table 4 with the full data results in Table 3 , we can see that the magnitude of the spending difference between multichannel and mono-channel customers is slightly lower under the PSM models. On average, under PSM (full data), the first year difference is $\$ 90.60$ (\$94.97) and the second year difference is $\$ 36.67$ (\$43.45).

\subsubsection{The Effect of Control Variables}

The only customer characteristics variable that is significant $(p<0.01)$ across all five models is the age of the household head, suggesting that younger customers spend more than older one. The effects are similar in magnitude to those obtained using the full data. They range from $\beta=-0.90$ (A-B GMM) to $\beta=-0.54$ (LDV). Unlike the full data results, all the other customer characteristics are insignificant $(p<0.05)$. (In the POLS models, past purchase incidence has a significant impact $(p<0.01)$ on spending and customer with longer tenure spend significantly $(p<0.05)$ less.)

For the marketing effort variables, the results are also quite similar to those using the full data. Catalogs have a significant positive impact $(p<0.001)$ on consumers' spending with effects ranging from $\beta=6.50$ (A-B GMM) to $\beta=7.34$ (FE). E-mail subscription also has a significant positive impact $(p<0.001)$ with estimates ranging from $\beta=59.21$ (FE) to $\beta=78.28$ (A-B GMM). The effect of number of e-mails sent is still significantly negative $(p<0.001)$ with a magnitude of about -2 across all the five models.

As in the full data analysis, the state dependence variable shows a significant positive effect $(\beta=0.38, p<0.001)$ for the LDV model, but its effect is negative $(\beta=-0.20, p<0.001)$ for the A-B GMM model. Except for the FD model, the time trend effects have similar decay in customers' spending over time. The FD model, however, shows increased trend over time.
5.3 Results Based on Propensity Score Matching Using Household Characteristics

This PSM method matches households based on their stated demographic and socioeconomic factors rather than relying on zip code-level data. As such matching puts the highest restrictions to create matched pairs, the size of the resulting dataset is approximately $31 \%$ the size of the original data. Table 5 presents the results obtained by the five econometric models applied to these data. Overall, the estimation results in Table 5 are quite consistent with those in Tables 4 and 3. This suggests that matching techniques using aggregate level data (such as US Census demographics) produce similar results to those of matching methods based on individual-level data.

\subsubsection{The Effect of Multichannel Usage}

The effect of multichannel usage is quite consistent and close in magnitude across the two matching methods. On average, across all the models, the boost in revenues in the first year of being multichannel is $\$ 91.27$ and in the second year is $\$ 36.89$ (all effects are significant, $p<0.001$ ). By the third year, the difference between the multichannel and mono-channel customers' spending is no longer significant $(p>0.05)$, with the exception of the FE model $\left(\rho_{3}=39.33 ; p<0.01\right)$.

\subsubsection{The Effect of Control Variables}

Except for few differences, the effects of the control variables are also similar across the two matching methods. Younger customers spend significantly more than older ones $(p<0.05)$. Number of catalogs received and e-mail subscription have a significant positive impact on spending $(p<0.00)$, whereas number of e-mails sent has a significant negative impact $(p<$ 0.001). We also obtain similar persistence and time trend effects. A difference in the results stems from the POLS model, where the effects of number of children become significant $(p<0.05)$.

\section{Discussion}

Except for the FD model, the effects are similar in magnitude across all regressions. This is not surprising as the FD model measures first differences, whereas the other regressions examine the relation between the dependent variable and regressors.

Our key finding is that multichannel customers spend significantly more than mono-channel customers in the short run but revert to their regular spending pattern over time. One potential explanation for this result is the novelty effect. According to the novelty effect, when customers start using 
a new channel, they derive epistemic (novelty) value from trying and learning new things [14, 41]. This epistemic value results in excitement [42], positive attitudes towards the purchase [18], higher customer satisfaction [42], and amplified consumption patterns [15, 43]. Cantor [44] and Sheth et al. [16] find that customers who are motivated by novelty value often return to their regular consumption patterns after satisfying their need for change. For some products and services, reverting to regular consumption patterns may take a few years. For example, Howard and Crompton [17] find that the boost in attendance and revenues associated with a new stadium may last several years.

Another potential explanation for the similarity of multichannel and mono-channel customers in the long run lies in the consequences of using the online channel. Ansari et al. [7] find that when customers use the Internet channel over time, they tend to buy less frequently from the firm. This suggests that customers may start to compare competitors' products and prices and become price-sensitive over time [9]. That is, as multichannel customers (who use an online channel) become more comfortable using the Internet, they start to buy from competitors.

\section{Conclusion}

This paper investigates the consequences of multichannel shopping on consumers' spending. It validates previously established theories suggesting that multichannel customers on average spend more. However, we find that multichannel customers increase their overall spending initially and return to their regular spending pattern over time. This may be due to increased customer switching behavior stemming from the online channel use. It can also be explained by the novelty effect, whereby adopters of new technologies and products increase their consumption for a limited time and regress to their regular spending pattern in due course.

Our results are based on observational data which are affected by self-selection: heavy spenders and sophisticated customers are more likely to become multichannel. That is, the direction of causality between multichannel shopping and customers' spending is not clear. To address this issue, we use different panel data econometric models and combine them with two propensity score matching methods. Our results are very consistent across all analyses. Further, we empirically demonstrate that using matched pairs based on aggregate- and household-level characteristics produces quite similar results. This finding suggests that matching techniques using aggregate level data (such as US Census demographics at zip code) produce reliable results and can control for self-selection bias. The findings also suggest that POLS estimates do a reasonable job of uncovering the key relations.
We validate previous findings that marketing activities, customer demographics, and socioeconomic factors influence customers' overall spending. Catalogs increase households' spending. E-mails, on the other hand, tell a different story: While e-mail subscriptions are positively correlated with spending, the number of e-mails received has a negative influence. The latter result implies that the overuse of e-mails creates irritation among retailer's customers. We find that younger customers with college education tend to spend more. In addition, the number of children in a household is negatively associated with spending, suggesting that having more children decreases a household's disposable income. Alternatively, these households are likely to be more price-sensitive and less loyal to the sponsoring firm.

Managerially, these findings indicate potential drawbacks of expanding channel structures for firms. Although it has been typically accepted that opening and maintaining new channels increases customers' lifetime value by creating multichannel customers [1-3], our results suggest that managers should be aware that the increased revenues associated with multichannel usage may not be sustained in the long run.

This paper is not free of limitations: first, our paper analyzed the long-term effects of multichannel shopping on customer's spending when a firm adds an online channel. Thus, it is possible that our results may not generalize when the firm adds a different type of channel. As preliminary evidence, we analyzed a similar longitudinal data (albeit much shorter) to examine whether our findings hold when the firm adds a bricks-and-mortar store. The results summarized in the Appendix indicate that our results are robust. Second, the data provider is a single firm that operates in mature markets. The trend showing a decline in spending might not arise to companies operating in new and growing industries. Third, as the firm sells durables and apparels, these results may not be generalizable to consumer goods that are frequently purchased. Finally, we do not separate consumers' incidence and purchase amount decisions. Separating these decisions (see for example, [7]) can provide further insights. Nonetheless, our results suggest that marketers can benefit from focusing on multichannel shoppers' behavior in the long run.

\section{Robustness Check, Regression on Bricks-and-Mortar Store Users}

In this appendix, we report the detailed results of our robustness checks that we performed to see if our findings hold when we measure the impact of multichannel usage in the long run, when customers start using a bricks-and-mortar store rather than an Internet channel.

It is possible that our results in this study are driven by the fact that the multichannel customers start to use the Internet 


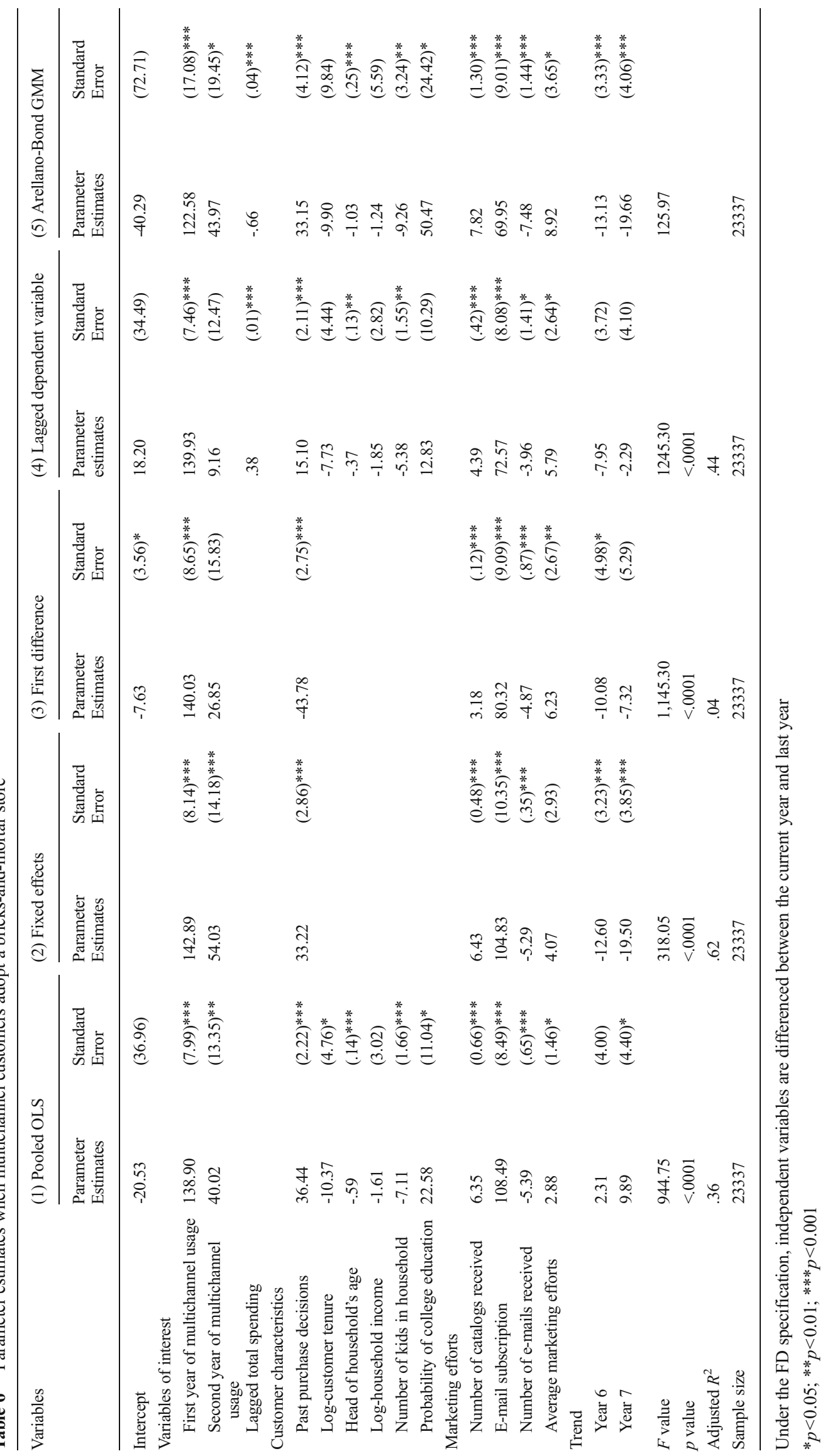


channel. Ansari et al. [7] find that when customers use the Internet channel over time, they tend to buy less frequently from the firm. As a result, it is possible that multichannel users who add other types of channels to their incumbent channel might act differently.

To address this concern, we analyze data on catalog customers who start using a conventional retail store channel. Bricks-and-mortar stores provide very different shopping experiences to the customers compared to Internet channels. For instance, retail stores offer complementary attributes to other types of channels, such as easing the return and exchange processes [21], providing aftersales service (Verhoef et al. [45]), and creating repeated exposure to a company's brand (Avery et al. [46]). Hence, one may expect that adopting a bricks-and-mortar store would lead customers to increase their spending over time. Pauwels and Neslin [21], Avery et al. [46], and Pancras et al. [47] find that, at the aggregate level, adding a new retail store increases total revenues of a firm in the long run. Our results in this study, on the other hand, suggest that this increase in aggregate sales is coming from either (i) newly acquired customers or (ii) a shortlived spike in incumbent customers' spending after they start using the physical store.

To control for any impact of type of new channel adopted, we also analyze data on households who began to use a conventional physical store: the sponsoring retailer has opened a bricks-and-mortar store on November 1, 2001, and gathered household-level data until September 1, 2004. These data provide about a 3-year time window to examine how multichannel customers' (who begin using physical store along with the catalog channel) spending alters over time.

Table 6 summarizes the estimation results of the five panel data econometrics models. Similar to our previous results, the estimates show that the multichannel customers (i) increase their spending in the first year they become multichannel and (ii) dramatically lower their spending in the second year of their multichannel usage.

\section{References}

1. Shankar V, Smith AK, Rangaswamy A (2003) Customer satisfaction and loyalty in online and offline environments. Int $\mathrm{J}$ Res Market 20(2):153-175

2. Hitt LM, Frei FX (2002) Do better customers utilize electronic distribution channels? The case of PC banking. Manag Sci 48(6): 732-748

3. Sousa R, Voss CA (2006) Service quality in multichannel services employing virtual channels. J Serv Res 8(4):356-371

4. Thomas JS, Sullivan UY (2005) Managing marketing communications with multichannel customers. J Market 69(4):239-251

5. Kumar V, Rajkumar V (2005) Who are the multichannel shoppers and how do they perform?: correlates of multichannel shopping behavior. J Interact Market 19(2):44-62
6. Venkatesan R, Kumar V, Nalini R (2007) Multichannel shopping: causes and consequences. J Market 71(2):114-132

7. Ansari A, Mela CF, Neslin SA (2008) Customer channel migration. J Market Res 45(1):60-76

8. Kushwaha, Tarun L, Shankar V (2008) Single channel vs. multichannel retail customers: correlates and consequences, working paper, Texas A\&M University, College Station, TX 77845

9. Blattberg, Robert C., Byung-Do Kim, and Scott A. Neslin. Database marketing: analyzing and managing customers. Springer, 2008.

10. Heckman JJ, Ichimura H, Todd P (1998) Matching as an econometric evaluation estimator. Rev Econ Stud 65(2):261-294

11. Dehejia RH, Wahba S (2002) Propensity score-matching methods for nonexperimental causal studies. Rev Econ Stat 84(1):151-161

12. Aral S, Muchnik L, Sundararajan A (2009) Distinguishing influencebased contagion from homophily-driven diffusion in dynamic networks. Proc Natl Acad Sci 106(51):21544-21549

13. Gensler, Sonja, Leeflang P, Skiera B (2012) Comparing methods to separate treatment from self-selection effects in an online banking setting. J Bus Res no. 0. Accessed September 14, 2012

14. Pihlström M, Brush GJ (2008) Comparing the perceived value of information and entertainment mobile services. Psychol Market 25(8):732-755

15. McQuiston DH (1989) Novelty, complexity, and importance as causal determinants of industrial buyer behavior. J Market 53(2):66-79

16. Sheth JN, Newman BI, Gross BL (1991) Consumption values and market choices: theory and applications. South-Western Pub, Cincinnati

17. Howard DR, Crompton JL (2003) An empirical review of the stadium novelty effect. Sport Market Q 12(2):111-116

18. La Ferle C, Gayatri K, Edwards SM (2013) Factors impacting responses to cause-related marketing in India and the United States: novelty, altruistic motives, and company origin. J Bus Res 66(3): 364-373

19. Neslin SA, Grewal D, Leghorn R, Shankar V, Teerling ML, Thomas JS, Verhoef PC (2006) Challenges and opportunities in multichannel customer management. J Serv Res 9(2):95-112

20. Avery J, Steenburgh TJ, Deighton J, Caravella M (2011) Adding bricks to clicks: predicting the patterns of cross-channel elasticities over time. SSRN eLibrary (July 18, 2011)

21. Pauwels K, Neslin SA (2008) Building with bricks and mortar: the revenue impact of opening physical stores in a multichannel environment. Working Paper, Tuck School of Business, Dartmouth College, 2008

22. Heckman J, Navarro-Lozano S (2004) Using matching, instrumental variables, and control functions to estimate economic choice models. Rev Econ Stat 86(1):30-57

23. Gensler S, Leeflang P, Skiera B (2012) Impact of online channel use on customer revenues and costs to serve: considering product portfolios and self-selection. Int J Res Market 29(2):192-201

24. Angrist JD, Pischke JS (2008) Mostly harmless econometrics: An empiricist's companion. Princeton University Press, Princeton, NJ

25. Mattilla M, Karjaluoto H, Pento T (2003) Internet banking adoption among mature customers: early majority or laggards? J Serv Mark 17(5):514-528

26. Risselada, Hans, Verhoef PC, Bijmolt THA (2014) Dynamic effects of social influence and direct marketing on the adoption of hightechnology products. J Market 78.2:52-68

27. Card D, Krueger AB (1994) Minimum wages and employment: a case study of the fast-food industry in New Jersey and Pennsylvania. Am Econ Rev 84(4):772-793

28. Wangenheim FV, Bayón T (2007) Behavioral consequences of overbooking service capacity. J Market 71(4):36-47

29. Anderson TW, Hsiao C (1982). Formulation and estimation of dynamic models using panel data. J Econom 18(1):47-82 
30. Arellano M, Bond S (1991) Some tests of specification for panel data: Monte Carlo evidence and an application to employment equations. Rev Econ Stud 58(2):277-297

31. Degeratu AM, Rangaswamy A, Jianan W (2000) Consumer choice behavior in online and traditional supermarkets: the effects of brand name, price, and other search attributes. Int J Res Market 17(1):55-78

32. Campbell D, Frei F (2010) Cost structure, customer profitability, and retention implications of self-service distribution channels: evidence from customer behavior in an online banking channel. Manag Sci 56(1):4-24

33. Mithas, S., Krishnan, M. S., \& Fornell, C. (2005). Why Do Customer Relationship Management Applications Affect Customer Satisfaction? Journal of Marketing, 69(4), 201-209

34. Smith JA, Todd PE (2005) Does matching overcome LaLonde's critique of nonexperimental estimators? J Econ 125(1-2):305-353

35. Acemoglu D, Johnson S, Robinson JA, Yared P (2008) Income and democracy. Am Econ Rev 98(3):808-842

36. Kushwaha TL, Shankar V (2013) "Single Channel vs. Multichannel Retail Customers: Correlates and Consequences." Working Paper, Texas A\&M Universit

37. Fox EJ, Montgomery AL, Lodish LM (2004) Consumer shopping and spending across retail formats. J Bus Res 77(S2):S25-S60

38. Pew Research Center (2003) "Spam: How is it Hurting Email and Degrading Life on the Internet," Pew Internet \& American Life, http://www.pewinternet.org/2003/10/22/spam-how-it-is-hurtingemail-and-degradinglife-on-the-internet/. Accessed 5 Dec 2014
39. Morimoto M, Chang S (2006) Consumers' attitudes toward unsolicited commercial e-mail and postal direct mail marketing methods: intrusiveness, perceived loss of control, and irritation. J Interac Adver 7(1):8-20

40. Ellis-Chadwick F, Doherty NF (2012) Web advertising: the role of email marketing. J Bus Res 65(6):843-848

41. Duman T, Mattila AS (2005) The role of affective factors on perceived cruise vacation value. Tour Manage 26(3): 311-323

42. Liu V, Khalifa M (2003) Determinants of satisfaction at different adoption stages of internet-based services. (J Assoc Inform Syst 4(1)

43. Coates D, Humphreys BR (2005) Novelty effects of new facilities on attendance at professional sporting events. Contemp Econ Pol 23(3): 436-455

44. Cantor GN (1968) Children's 'like-dislike' ratings of familiarized and nonfamiliarized visual stimuli. J Exp Child Psychol 6(4):651-657

45. Verhoef PC, Nelsin SA, Vroomen B (2007) "Multichannel Customer Management: Understanding the Research-shopper Phenomenon." Int J Res Mark 24(2):129-148

46. Avery J, Steenburgh TJ, Deighton J, Caravella M (2012). Adding bricks to clicks: Predicting the patterns of cross-channel elasticities over time. J Mark 76(3):96-111

47. Pancras J, SriramS, Kumar V (2012). Empirical Investigation of Retail Expansion and Cannibalization in a Dynamic Environment. Manag Sci 58(11):2001-2018 